\title{
A Retrospective Study on the Use of High-Dose Letrozole While Undergoing Ovarian Stimulation for Oocyte and Embryo Cryopreservation in Cancer Patients
}

\author{
Rahana Harjee' ${ }^{1}$ Jeffrey Roberts ${ }^{1,2}$ \\ ${ }^{1}$ University of British Columbia, Vancouver, Canada \\ ${ }^{2}$ Pacific Centre for Reproductive Medicine, Burnaby, Canada \\ Email: rahana.harjee@gmail.com
}

How to cite this paper: Harjee, R. and Roberts, J. (2022) A Retrospective Study on the Use of High-Dose Letrozole While Undergoing Ovarian Stimulation for Oocyte and Embryo Cryopreservation in Cancer Patients. Advances in Reproductive Sciences, 10, 19-26.

https://doi.org/10.4236/arsci.2022.101003

Received: January 9, 2022

Accepted: February 21, 2022

Published: February 24, 2022

Copyright $\odot 2022$ by author(s) and Scientific Research Publishing Inc. This work is licensed under the Creative Commons Attribution International License (CC BY 4.0).

http://creativecommons.org/licenses/by/4.0/ (c) (i) Open Access

\begin{abstract}
Objective: To determine the efficacy of letrozole in suppressing estradiol levels during ovarian stimulation in cancer patients. Methods: A retrospective chart review of cancer patients undergoing ovarian stimulation for fertility preservation between 2014-2019 at a private university-affiliated fertility clinic in Canada was conducted. Ovarian stimulation was completed with no letrozole (Group A, $n=10$ ), and adjuvant daily letrozole use at 5.0 (Group $\mathrm{B}, \mathrm{n}=34$ ) or $7.5 \mathrm{mg}$ (Group $\mathrm{C}, \mathrm{n}=61$ ). The primary outcomes were peak estradiol levels and oocyte yield. ANOVA with a post hoc two-tailed t-test assuming equal variance was utilized as a statistical method. Result(s): Patient age and AFC count were not different between groups. The yield of mature eggs was not different at each letrozole dose; $9.2 \pm 6.0,13.9 \pm 6.5$ and $12.7 \pm$ 7.2 for Groups A to C respectively $(p=0.18)$. Mean estradiol levels ( $\mathrm{pmol} / \mathrm{L})$ were reduced in a dose-dependent manner; $7432 \pm 4553$ for Group A, 2072 \pm 1656 for Group B, and $1445 \pm 1238$ for Group C (A vs. C, $p<0.01$ and B vs. $C, p<0.04)$. Conclusion(s): The use of letrozole during ovarian stimulation for oocyte and embryo cryopreservation in cancer patients can maintain physiologic estradiol levels, while ensuring satisfactory oocyte and embryo yield. Letrozole can, therefore, minimize the theoretical risk of stimulating residual and metastatic diseases, while still optimizing future fertility outcomes.
\end{abstract}

\section{Keywords}

Ovarian Stimulation, Oocyte Preservation, Fertility Preservation, Cancer 


\section{Introduction}

With earlier diagnosis and treatment initiation, survival rates for cancers in young women and men have never been higher [1]. Unfortunately, treatment often comes at the cost of future infertility since many patients receive chemotherapeutic protocols that are gonadotoxic [2] [3]. For female patients that have not completed childbearing, oocyte and embryo cryopreservation through assisted reproductive technologies is still the standard fertility preservation technique worldwide.

To achieve the optimal yield of oocytes that we strive for, supraphysiologic estrogen levels will be generated [2] [3] [4] [5] [6]. Breast cancer is the most common malignancy in reproductive age women, and despite no clinical evidence that ovarian stimulation is detrimental for the cure, there remains at least a theoretical risk of stimulating residual and metastatic diseases [7] [8]. At our facility, we use the aromatase inhibitor letrozole during ovarian stimulation in all patients with cancer to suppress estradiol levels, and have altered practice over time with higher daily doses to maximize the response. This is a retrospective analysis of our oocyte and embryo cryopreservation treatment outcomes with no letrozole, with the addition of $5 \mathrm{mg}$ or $7.5 \mathrm{mg}$ of letrozole daily.

\section{Materials and Methods}

\subsection{Patients}

We retrospectively reviewed the ovarian stimulation cycles of cancer patients undergoing fertility preservation for oocyte and embryo cryopreservation at our facility from 2006 to 2019. Patients were grouped into those receiving no letrozole (Group A, $\mathrm{n}=10$ ), $5 \mathrm{mg}$ letrozole daily (Group B, $\mathrm{n}=34$ ) and $7.5 \mathrm{mg}$ letrozole daily (Group C, $n=61$ ). Clinical research ethics board approval was obtained for this study.

\subsection{Ovarian Stimulation}

A GnRH-antagonist protocol was utilized, with patients initiating daily subcutaneous FSH with Bravelle (Ferring Canada), Puregon (Merck Canada), Gonal-f (EMD Serono), or hMG Menopur (Ferring Canada), starting on day 2 or 3 of menses. Daily GnRH antagonist with Orgalutran (Merck Canada) or Cetrotide (EMD Serono) was administered when the lead follicle reached $12 \mathrm{~mm}$ or day 5 of FSH use, and continued until the day of trigger. Patients in Group B and Group C initiated letrozole from day 4 of FSH administration after obtaining a serum estradiol level.

Treatment monitoring consisted of serial serum estradiol levels and follicles measurement by transvaginal ultrasound, and gonadotropins continued until a mean lead follicle diameter of at least $20 \mathrm{~mm}$ was achieved in 2 to 3 lead follicles. Oocyte maturation was triggered with either $0.2 \mathrm{mg}$ triptorelin (Decapeptyl, (Ferring Canada) and/or hCG at doses between 1500 and 10,000 IU, and oocyte retrieval performed 36 hours later. In all patients (Groups A, B, and C), subsequent 
cryopreservation of either oocytes or embryos was performed fertilization by ICSI or standard IVF culture.

Outcomes measures included peak estradiol levels, oocyte and embryo yield, and duration of FSH use.

\subsection{Statistical Analysis}

ANOVA with a post hoc two-tailed t-test assuming equal variance were the statistical methods used to compare outcomes.

\section{Results}

Patient characteristics are displayed in Table 1. In the group of patients not taking letrozole $(\mathrm{n}=10)$ had a mean age of 30.3 years, while the mean age of the 5 $\mathrm{mg}(\mathrm{n}=34)$ and $7.5 \mathrm{mg}(\mathrm{n}=61)$ groups were 32.4 years and 31.8 years respectively. Diagnoses included breast cancer, ovarian cancer, lymphoma, endometrial cancer, cervical cancer, colon cancer, and rhabdomyosarcoma (Table 2).

The baseline evaluation included antral follicle counts in patients which showed no significant differences between groups $(p=0.25)$. Oocyte cryopreservation was performed in 52 patients (5 in Group A, 15 in Group B, and 32 in Group C), where results are shown in Figure 1. The yield of mature oocytes was not different between groups (Table 3). Embryo cryopreservation was performed in 53 patients ( 5 in Group A, 19 in Group B, and 30 in Group C), as displayed in

Table 1. Patient demographics.

\begin{tabular}{ccccc}
\hline & $\begin{array}{c}\mathbf{0} \mathrm{mg} \text { Letrozole } \\
\text { (Group A) } \\
\mathbf{n}=10\end{array}$ & $\begin{array}{c}\mathbf{5} \text { mg Letrozole } \\
(\text { Group B }) \\
\mathbf{n}=\mathbf{3 4}\end{array}$ & $\begin{array}{c}7.5 \mathrm{mg} \text { Letrozole } \\
(\text { Group C) } \\
\mathbf{n}=\mathbf{6 1}\end{array}$ & p value \\
\hline Mean Age (years) & 30.3 & 32.4 & 31.8 & 0.36 \\
Mean AFC & $19.3 \pm 9.4$ & $15.4 \pm 6.3$ & $18.6 \pm 8.5$ & 0.25 \\
\hline
\end{tabular}

Table 2. Patient diagnoses.

\begin{tabular}{ccc}
\hline & \# of patients & \% of patients (n = 105) \\
\hline Appendiceal & 1 & 0.9 \\
Brain & 1 & 0.9 \\
Breast & 77 & 73.3 \\
Cervical & 5 & 4.8 \\
Colon & 2 & 1.9 \\
Endometrial & 2 & 1.9 \\
Lymphoma & 13 & 12.4 \\
Ovarian & 2 & 1.9 \\
Rectal & 1 & 0.9 \\
Rhabdomyosarcoma & 1 & 0.9 \\
\hline
\end{tabular}


Table 3. Summary of results.

\begin{tabular}{|c|c|c|c|c|}
\hline & $\begin{array}{c}0 \text { mg Letrozole } \\
\text { (Group A) }\end{array}$ & $\begin{array}{c}5 \text { mg Letrozole } \\
\text { (Group B) }\end{array}$ & $\begin{array}{c}7.5 \text { mg Letrozole } \\
\text { (Group C) }\end{array}$ & $\mathrm{p}$ value \\
\hline & & & & 0.05 (A vs $\mathrm{B})$ \\
\hline \multirow[t]{3}{*}{ Mature Oocytes } & $9.2 \pm 6.0$ & $13.9 \pm 6.6$ & $12.7 \pm 7.2$ & $0.16(\mathrm{~A}$ vs $\mathrm{C})$ \\
\hline & & & & 0.43 (B vs C) \\
\hline & & & & $0.05(\mathrm{~A}$ vs $\mathrm{B})$ \\
\hline \multirow[t]{3}{*}{ Embryos } & $4.8 \pm 3.3$ & $9.2 \pm 4.4$ & $5.2 \pm 4.3$ & 0.82 (A vs $\mathrm{C})$ \\
\hline & & & & $<0.01$ (B vs C) \\
\hline & & & & $<0.01(\mathrm{~A}$ vs $\mathrm{B})$ \\
\hline \multirow[t]{3}{*}{ Estradiol (pmol/L) } & $7432 \pm 4553$ & $2072 \pm 1656$ & $1445 \pm 1238$ & $<0.01(\mathrm{~A}$ vs $\mathrm{C})$ \\
\hline & & & & 0.04 (B vs C) \\
\hline & & & & 0.97 (A vs $\mathrm{B})$ \\
\hline \multirow[t]{2}{*}{ Cycle Length (days) } & $10.3 \pm 1.83$ & $10.3 \pm 2.37$ & $10.9 \pm 2.30$ & 0.39 (A vs $\mathrm{C})$ \\
\hline & & & & 0.27 (B vs $\mathrm{C})$ \\
\hline
\end{tabular}

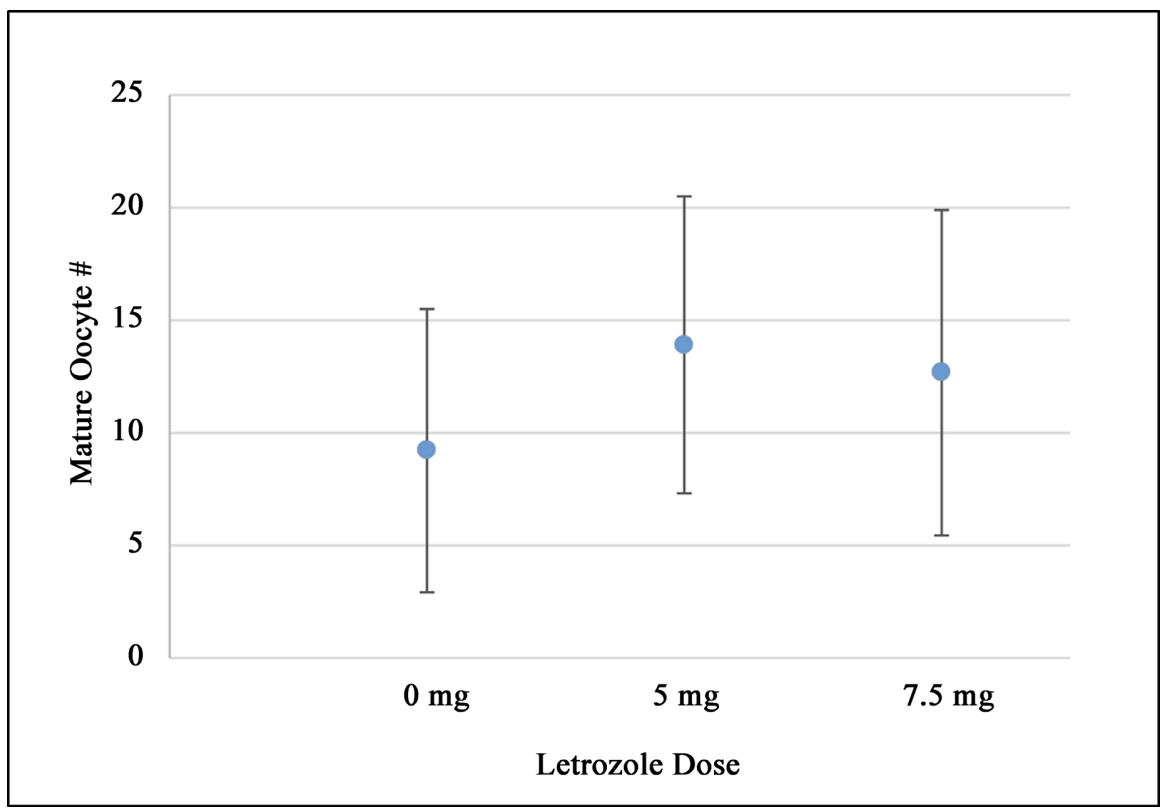

Figure 1. Mean mature oocyte yield by letrozole dose with $95 \%$ confidence interval.

Figure 2. Group C had a lower embryo yield compared to Group B (5.2 \pm 4.3 vs. $9.2 \pm 4.4, \mathrm{p}<0.01)$; however, there was no difference between Group A and B, or Group B and C (Table 3).

Peak estradiol levels declined in a dose-dependent manner with patients receiving $7.5 \mathrm{mg}$ daily letrozole (Group C) having the lowest peak serum estradiol levels, which can be observed in Figure 3. There was no difference in cycle length between the 3 groups with a range of 10.3 to 10.9 days. 


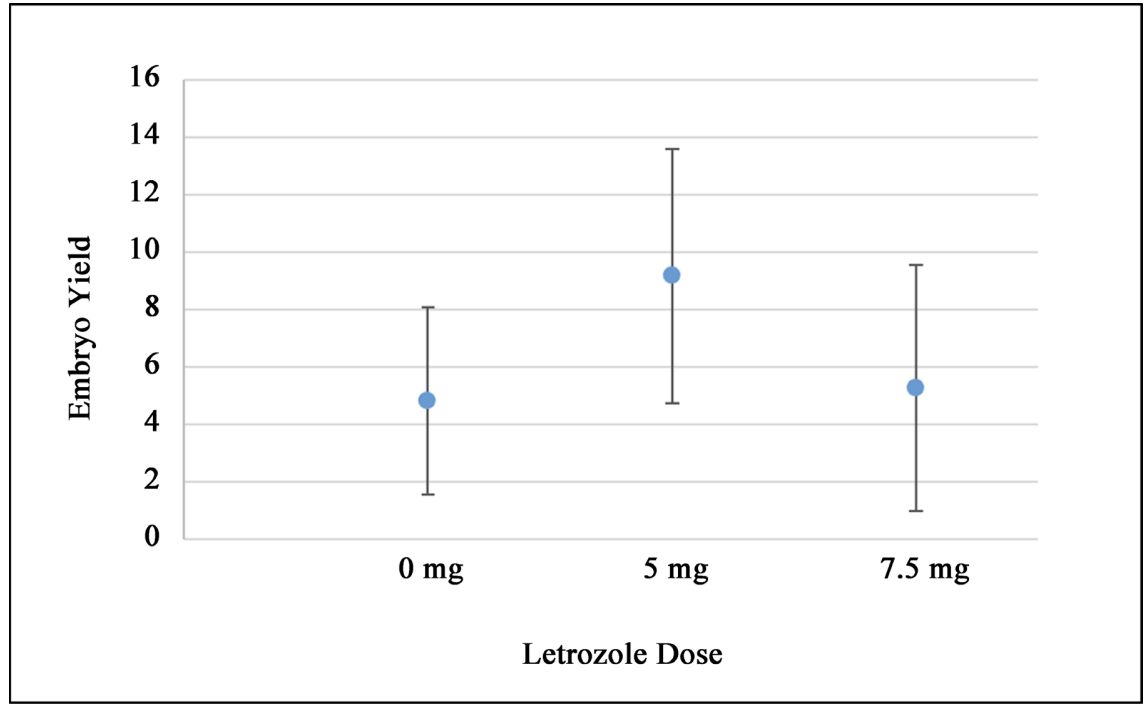

Figure 2. Mean embryo yield by letrozole dose with $95 \%$ confidence interval.

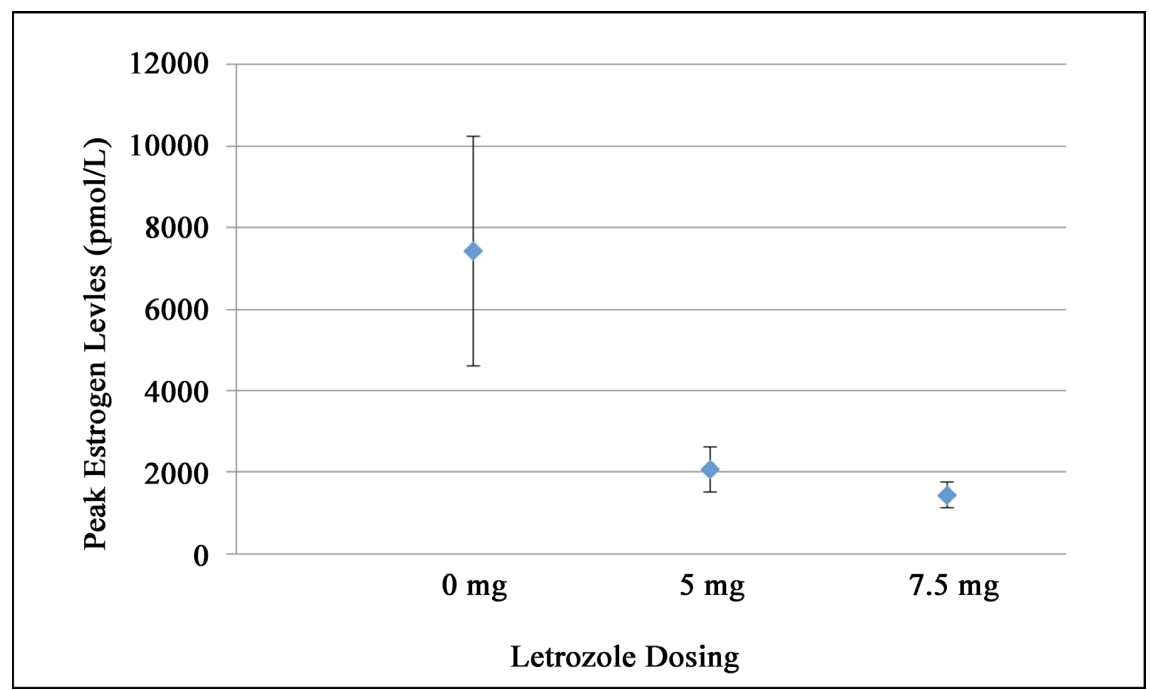

Figure 3. Mean serum peak estradiol level (pmol/L) by letrozole dose with $95 \%$ confidence interval.

\section{Discussion}

We demonstrated a dose-dependent suppression of peak estradiol levels with the use of letrozole in cancer patients undergoing controlled ovarian hyperstimulation for oocyte and embryo cryopreservation, with $7.5 \mathrm{mg}$ producing levels within the physiologic range. Importantly letrozole use did not appear to impact on oocyte of embryo yield from the treatment.

Many breast cancer tumor cells are estrogen receptor positive, and accordingly are susceptible to environments with estrogen excess [9] [10]. By definition neoplastic tissue is chaotic so even tumors that are classified as receptor negative will contain a small percentage of receptor-positive cell [11] [12]. Serum estradiol levels reach supraphysiologic levels during controlled ovarian stimulation, commonly in excess of $5000 \mathrm{pmol} / \mathrm{mL}$, with peak levels in a natural cycle typically 
only achieving approximately $1000 \mathrm{pmol} / \mathrm{mL}$. Observational data supports the safety of these technologies in terms of recurrence of breast cancer and contralateral disease, however follow-up periods were limited (5 years or less) [13]-[18]. Although no clinical data currently exist, iatrogenic increases in estrogen exposure could in theory stimulate subclinical disease in estrogen-dependent neoplasia, therefore any therapy that minimizes serum levels makes clinical sense.

Two strategies are commonly employed to minimize estrogen exposure in cancer patients undergoing ovarian stimulation, recovering oocytes from an unstimulated IVF cycle, or use of cytoprotective agents like aromatase inhibitors and tamoxifen [4] [7]. Aromatase inhibitors have proven efficacious as an adjuvant therapy for the management of micrometastatic disease [15] [19] [20] [21]. More importantly for the breast cancer patient, they also suppress ovarian estradiol production during controlled ovarian hyperstimulation. With concurrent use of aromatase inhibitors, high doses of gonadotropins can be administered to maximize embryo yield while minimizing estradiol levels [3] [22]. Several retrospective reviews on the use of letrozole in ovarian stimulation protocols in breast cancer patients have supported the suppressive effects on estradiol levels, but showed variable oocyte yields [2] [3] [23] [24] [25] [26]. Letrozole has also found widespread use in reproductive medicine as an ovulation induction agents and adjunct in IVF protocols [27]. Since the follicles remain hormonally active for at least another week beyond retrieval of the oocytes, we continue letrozole for further seven days. For simplicity sake, our patients are provided with the standard 30 tablet box of $2.5 \mathrm{mg}$ letrozole and instructed to take three tablets a day from stimulation day 4 until completion of the box.

\section{Conclusion}

This study demonstrated that the use of letrozole during ovarian stimulation for oocyte and embryo cryopreservation in cancer patients can maintain estradiol levels within a physiologic level, while maintaining an acceptable egg and embryo yield. With little apparent impact on the major outcomes with fertility preservation, reducing estrogen load in these cancer patients clinically makes sense, particularly those with estrogen-dependent tumours. This was a retrospective analysis and a randomized control trial is needed to better study the effects of letrozole use in egg and embryo cryopreservation ART cycles.

\section{Conflicts of Interest}

The authors declare no conflicts of interest regarding the publication of this paper.

\section{References}

[1] Canadian Cancer Statistics Advisory Committee (2018) Canadian Cancer Statistics 2018. Canadian Cancer Society, Toronto.

[2] Oktay, K., Hourvitz, A., Sahin, G., et al. (2006) Letrozole Reduces Estrogen and Gon- 
adotropin Exposure in Women with Breast Cancer Undergoing Ovarian Stimulation before Chemotherapy. The Journal of Clinical Endocrinology \& Metabolism, 91, 38853890. https://doi.org/10.1210/jc.2006-0962

[3] Vizcaino, M.A.C., Corchado, A.R., Cuadri, M.E., Comadran, M.G., Brassesco, M. and Carreras, R. (2012) The Effects of Letrozole on Ovarian Stimulation for Fertility Preservation in Cancer-Affected Women. Reproductive Biomedicine Online, 24, 606-610. https://doi.org/10.1016/j.rbmo.2012.02.020

[4] Munoz, E., Gonzalez, N., Munoz, L., Aguilar, J. and Velasco, J.A. (2015) Ovarian Stimulation in Patients with Breast Cancer. Ecancermedicalscience, 9, 504.

https://doi.org/10.3332/ecancer.2015.504

[5] Sunkara, S.K., Rittenberg, V., Raine-Fenning, N., Bhattacharya, S., Zamora, J. and Coomarasamy, A. (2011) Association between the Number of Eggs and Live Birth in IVF Treatment: An Analysis of 400135 Treatment Cycles. Human Reproduction, 26, 17681774. https://doi.org/10.1093/humrep/der106

[6] Milachich, T. and Shterev, A. (2016) Are there Optimal Numbers of Oocytes, Spermatozoa and Embryos in Assisted Reproduction? JBRA Assisted Reproduction, 20, 142-149. https://doi.org/10.5935/1518-0557.20160032

[7] Shapira, M., Raanani, H. and Meirow, D. (2015) IVF for Fertility Preservation in Breast Cancer Patients-Efficacy and Safety Issues. Journal of Assisted Reproduction and Genetics, 32, 1171-1178. https://doi.org/10.1007/s10815-015-0519-x

[8] Cakmak, H. and Rosen, M.P. (2013) Ovarian Stimulation in Cancer Patients. Fertility and Sterility, 99, 1476-1484. https://doi.org/10.1016/j.fertnstert.2013.03.029

[9] Prest, S.J., May, F.E. and Westley, B.R. (2002) The Estrogen-Regulated Protein, TFF1, Stimulates Migration of Human Breast Cancer Cells. FASEB Journal, 16, 592-594. https://doi.org/10.1096/fj.01-0498fje

[10] Allred, C.D., Ju, Y.H., Allred, K.F., Chang, J. and Helferich, W.G. (2001) Dietary Genistin Stimulates Growth of Estrogen-Dependent Breast Cancer Tumors Similar to That Observed with Genistein. Carcinogenesis, 22, 1667-1673. https://doi.org/10.1093/carcin/22.10.1667

[11] Babayan, A., Hannemann, J., Spotter, J., Muller, V., Pantel, K. and Joosse, S.A. (2013) Heterogeneity of Estrogen Receptor Expression in Circulating Tumor Cells from Metastatic Breast Cancer Patients. PLoS ONE, 8, e75038. https://doi.org/10.1371/journal.pone.0075038

[12] Gonzalez-Angulo, A.M., Morales-Vasquez, F. and Hortobagyi, G.N. (2007) Overview of Resistance to Systemic Therapy in Patients with Breast Cancer. Advances in Experimental Medicine and Biology, 608, 1-22.

https://doi.org/10.1007/978-0-387-74039-3 1

[13] Azim, A.A., Costantini-Ferrando, M. and Oktay, K. (2008) Safety of Fertility Preservation by Ovarian Stimulation with Letrozole and Gonadotropins in Patients with Breast Cancer: A Prospective Controlled Study. Journal of Clinical Oncology: Official Journal of the American Society of Clinical Oncology, 26, 2630-2635. https://doi.org/10.1200//CO.2007.14.8700

[14] Kim, J., Turan, V. and Oktay, K. (2016) Long-Term Safety of Letrozole and Gonadotropin Stimulation for Fertility Preservation in Women with Breast Cancer. The Journal of Clinical Endocrinology and Metabolism, 101, 1364-1371. https://doi.org/10.1210/jc.2015-3878

[15] Miller, W.R. (2006) Aromatase and the Breast: Regulation and Clinical Aspects. Maturitas, 54, 335-341. https://doi.org/10.1016/j.maturitas.2006.04.020

[16] Love, R.R., Van Dinh, N., Quy, T.T., et al. (2008) Survival after Adjuvant Oophorectomy and Tamoxifen in Operable Breast Cancer in Premenopausal Women. Journal 
of Clinical Oncology: Official Journal of the American Society of Clinical Oncology, 26, 253-257. https://doi.org/10.1200/JCO.2007.11.6061

[17] Howell, A., Sims, A.H., Ong, K.R., Harvie, M.N., Evans, D.G. and Clarke, R.B. (2005) Mechanisms of Disease: Prediction and Prevention of Breast Cancer-Cellular and Molecular Interactions. Nature Clinical Practice Oncology, 2, 635-646. https://doi.org/10.1038/ncponc0361

[18] Henderson, I.C., Garber, J.E., Breitmeyer, J.B., Hayes, D.F. and Harris, J.R. (1990) Comprehensive Management of Disseminated Breast Cancer. Cancer, 66, 1439-1448. https://doi.org/10.1002/1097-0142(19900915)66:14+<1439::AID-CNCR2820661421 3.0.CO;2-M

[19] Fisher, B., Costantino, J., Redmond, C., et al. (1989) A Randomized Clinical Trial Evaluating Tamoxifen in the Treatment of Patients with Node-Negative Breast Cancer Who Have Estrogen-Receptor-Positive Tumors. The New England Journal of Medicine, 320, 479-484. https://doi.org/10.1056/NEJM198902233200802

[20] Goss, P.E., Ingle, J.N., Martino, S., et al. (2003) A Randomized Trial of Letrozole in Postmenopausal Women after Five Years of Tamoxifen Therapy for Early-Stage Breast Cancer. The New England Journal of Medicine, 349, 1793-1802.

https://doi.org/10.1056/NEJMoa032312

[21] Howell, A. and Locker, G.Y. (2005) Defining the Roles of Aromatase Inhibitors in the Adjuvant Treatment of Early-Stage Breast Cancer. Clinical Breast Cancer, 6, 302-309. https://doi.org/10.3816/CBC.2005.n.032

[22] Oktay, K., Buyuk, E., Davis, O., Yermakova, I., Veeck, L. and Rosenwaks, Z. (2003) Fertility Preservation in Breast Cancer Patients: IVF and Embryo Cryopreservation after Ovarian Stimulation with Tamoxifen. Human Reproduction, 18, 90-95. https://doi.org/10.1093/humrep/deg045

[23] Pu, D., Wu, J. and Liu, J. (2011) Comparisons of GnRH Antagonist versus GnRH Agonist Protocol in Poor Ovarian Responders Undergoing IVF. Human Reproduction, 26, 2742-2749. https://doi.org/10.1093/humrep/der240

[24] Ben-Haroush, A., Wertheimer, A., Klochendler, E., Sapir, O., Shufaro, Y. and Oron, G. (2018) Effect of Letrozole Added to Gonadotropins in Controlled Ovarian Stimulation Protocols on the Yield and Maturity of Retrieved Oocytes. Gynecological Endocrinology. The Official Journal of the International Society of Gynecological Endocrinology, 35, 324-327. https://doi.org/10.1080/09513590.2018.1534950

[25] Revelli, A., Porcu, E., Levi Setti, P.E., Delle Piane, L., Merlo, D.F. and Anserini, P. (2013) Is Letrozole Needed for Controlled Ovarian Stimulation in Patients with Estrogen Receptor-Positive Breast Cancer? Gynecological Endocrinology: The Official Journal of the International Society of Gynecological Endocrinology, 29, 993-996. https://doi.org/10.3109/09513590.2013.819083

[26] Goldrat, O., Gervy, C., Englert, Y., Delbaere, A. and Demeestere, I. (2015) Progesterone Levels in Letrozole Associated Controlled Ovarian Stimulation for Fertility Preservation in Breast Cancer Patients. Human Reproduction, 30, 2184-2189. https://doi.org/10.1093/humrep/dev155

[27] Schoolcraft, W.B., Surrey, E.S., Minjarez, D.A., Stevens, J.M. and Gardner, D.K. (2008) Management of Poor Responders: Can Outcomes Be Improved with a Novel Gonadotropin-Releasing Hormone Antagonist/Letrozole Protocol? Fertility and Sterility, 89, 151-156. https://doi.org/10.1016/j.fertnstert.2007.02.013 